\title{
PROGRAMAS DE CUMPLIMIENTO NORMATIVO EN MATERIA DE COMPETENCIA. ESTUDIO DE LA GUÍA ESPAÑOLA Y OTRAS EXPERIENCAS DE DERECHO COMPARADO*
}

\section{COMPLIANCE PROGRAMMES IN RELATION TO ANTITRUST. STUDY OF THE SPANISH GUIDE AND OTHER COMPARATIVE LAW EXPERIENCES}

\author{
María Flora Martín Moral \\ Profesora Contratada Doctora de Derecho Mercantil \\ Universidad de Valladolid
}

Recibido: 15.06.2021 / Aceptado: 07.07.2021

DOI: https://doi.org/10.20318/cdt.2021.6264

Resumen: El presente trabajo tiene por objeto comparar la situación española, anterior y posterior a la Guía de la CNMC sobre programas de cumplimiento normativo en relación con la defensa de la competencia, de 10 de junio de 2020, con otras experiencias tomadas del Derecho Comparado y con el criterio seguido por la Comisión Europea, reparando en la determinación de los requisitos de eficacia de los programas cumplimiento y en su papel a la hora de establecer el importe de las sanciones.

Palabras clave: defensa de la competencia, programa de cumplimiento normativo, autoridad de competencia, sanción.

Abstract: This paper aims to compare the Spanish situation, before and after the CNMC Guide on compliance programmes in relation to antitrust, of 10 June 2020, with other experiences from comparative law and with the criteria followed by the European Commission. We pay special attention to the determination of the effectiveness requirements of compliance programmes and to their role in stablishing the amount of penalties.

Keywords: antitrust, compliance programmes, competition authority, penalty

Sumario: I. Introducción: El auge de los programas de compliance en materia de competencia. II. Comisión Europea: "La importancia de cumplir". 1. Estrategias dirigidas a prevenir la infracción de las normas de defensa de la competencia. 2. Cómo limitar la exposición de la empresa cuando ya ha fallado la estrategia. III. Guías sobre compliance en materia de competencia en algunos países de nuestro entorno. 1. Reino Unido. A) Introducción. B) Programas de cumplimiento eficaces. C) Determinación del importe de la sanción. 2 Francia. A) Introducción. B) Programas de cumplimiento eficaces. C) Determinación del importe de la sanción. 3. Italia. A) Introducción. B) Programas de cumplimiento eficaces. C) Determinación del importe de la sanción. IV. Programas de compliance en materia de competencia en España. 1. Los programas de compliance en relación con la defensa de la competencia antes de la Guía de la CNMC. 2. Guía de la CNMC de programas de compliance en relación con la defensa de la competencia. A) Introducción. B) Programas de cumplimiento eficaces según la Guía de la CNMC. C) Consecuencias derivadas de la implantación de un programa de cumplimiento eficaz en los expedientes abiertos por la CNMC. 3. La aplicación de las previsiones de la Guía de la CNMC: Resolución de la CNMC de 11 de mayo de 2021, en el expediente S/DC/0627/18, Consultoras. V. Consideraciones finales.

*Este trabajo se ha realizado al amparo de los Proyectos de Investigación del Ministerio de Ciencia, Innovación y Universidades: "El impacto de la economía digital en el Derecho de la Competencia y la Distribución: del Big Data al Blockchain" (RTI2018-094201-B-C22) y “Ganancias ilícitas y Derecho Penal” (RTI2018-094287-B-I00). 


\section{Introducción: El auge de los programas de compliance en materia de competencia}

1. La CNMC, en su Guía sobre los programas de cumplimiento en relación con las normas de defensa de la competencia, de 10 de junio de 2020, define los programas de cumplimiento como "herramientas que permiten a los operadores económicos prevenir, detectar y reaccionar de manera temprana ante conductas ilícitas, susceptibles de generar responsabilidad penal y administrativa y afectar a su reputación".

2. La previsión del art. 31 bis en el Código Penal (en adelante, CP), eximiendo de responsabilidad penal a las personas jurídicas que hayan adoptado y ejecutado eficazmente un programa de prevención de riesgos penales o compliance, ha generado una tendencia favorable a la incorporación en las empresas de programas de cumplimiento normativo ${ }^{1}$.

Para el Derecho Penal, los beneficios son obvios. El citado precepto prevé, bajo la concurrencia determinadas condiciones -véase el art. 31 bis 2 y 4 del CP-, la posible exención de responsabilidad para aquellas empresas que cuenten con un programa de compliance penal antes de la comisión del delito o, en caso de acreditación parcial de las mencionadas circunstancias, su atenuación. El propio legislador concreta, en el art. 31. bis $5 \mathrm{CP}$, los requisitos que han de cumplir los citados modelos de organización y gestión. Asimismo, el art. 31. quarter CP considera, como atenuante, las medidas de compliance adoptadas después de la comisión del delito.

3. En el ámbito del Derecho de la Competencia, muchas empresas han formulado programas que pretenden evitar o detectar, de forma temprana, comportamientos anticompetitivos. Sin embargo, el incentivo para hacerlo no resulta tan claro como en el Derecho Penal, ya que ni la Ley 15/2007, de 3 de julio, de Defensa de la Competencia (LDC), ni el Real Decreto 261/2008, de 22 de febrero, por el que se aprueba el Reglamento de Defensa de la Competencia (RDC), hacen mención a ningún tipo de medida de cumplimiento normativo.

Es innegable que la existencia de estos programas en materia de competencia facilita la participación de las empresas en los programas de clemencia y que, acogerse a un programa de clemencia, sí que permite la exención del pago de la multa a aquellas empresas que formen parte de un cártel y pongan en conocimiento de la autoridad de competencia su existencia, permitiendo iniciar una investigación; o la reducción de su importe, si la autoridad ya tenía conocimiento de dicho cártel, siempre y cuando se aporten elementos de prueba sustantivos, cumpliendo con los requisitos y condiciones establecidos en la LDC y en su normativa de desarrollo (arts. 65 y 66 LDC, en relación con los arts. 46 a 53 RDC).

Pero lo cierto es que, al margen de ese beneficio indirecto, hasta junio de 2020, fecha en la que la CNMC publica la ya citada Guía sobre programas de cumplimiento, nuestra autoridad de competencia había dado escaso valor a los programas de compliance en el ámbito de los expedientes sancionadores incoados por infracción de la Ley de Defensa de la Competencia, siendo considerados, solo en contadas ocasiones, un elemento moderador de la responsabilidad.

4. Hoy, la Guía reconoce expresamente a los programas de cumplimiento la capacidad de atenuar la responsabilidad de la empresa infractora y, en consecuencia, modular la sanción, tal y como ya contemplaban las autoridades de competencia de algunos países de nuestro entorno en documentos similares ${ }^{2}$.

\footnotetext{
${ }^{1}$ La Ley Orgánica 5/2010, de 22 de junio, por la que se modifica la Ley Orgánica 10/1995, de 23 de noviembre, del Código Penal, extiende la responsabilidad penal a la persona jurídica, considerando entre las circunstancias atenuantes "haber establecido, antes del comienzo del juicio oral, medidas eficaces para prevenir y descubrir los delitos que en el futuro pudieran cometerse con los medios o bajo la cobertura de la persona jurídica"(art. 31.bis 4), si bien es cierto, el impuso definitivo tiene lugar con la aprobación de la Ley Orgánica 1/2015, de 30 de marzo, por la que se modifica la Ley Orgánica 10/1995, de 23 de noviembre, del Código Penal, que regula de forma más detallada el compliance penal.

${ }^{2}$ Véase el trabajo de J. A. Rodríguez Mínguez, "Prevención de cárteles, promoción de la competencia y programas de cumplimiento", en de J. M. Beneyto Pérez y J. M. GonzÁlez-Orús (dirs.), La lucha contra los cárteles en España, Cizur Menor (Navarra), Aranzadi, 2015, en el que afirma, tras la citada reforma de 2015 del art. 31 bis del CP, que dotar de un valor a
} 
5. El presente trabajo tiene como objetivo comparar la situación española, anterior y posterior a la Guía, con otras experiencias tomadas del Derecho Comparado y con el criterio seguido por la Comisión Europea, reparando en la determinación de los requisitos de eficacia de los programas de cumplimiento y en su papel a la hora de establecer el importe de las sanciones.

\section{Comisión Europea: "La importancia de cumplir"}

6. La Comisión, como autoridad de competencia de la Unión Europea, muestra su preocupación por el correcto cumplimiento de las normas de defensa de la competencia, y en su Guía, La importancia de cumplir: Qué pueden hacer las compañias para respetar mejor las normas de competencia de la UE', llama a las empresas a adoptar medidas de compliance, dirigidas a prevenir ilícitos anticompetitivos.

\section{Estrategias dirigidas a prevenir la infracción de las normas de defensa de la competencia}

7. La Comisión invita a las empresas a definir una estrategia clara, adaptada a la realidad de cada empresa, con el objetivo de crear una cultura de cumplimiento. Considera la Comisión que dichas estrategias han de cumplir con los siguientes requisitos:

$1^{\circ}$ ) Identificar el riesgo general y la exposición individual: Una buena estrategia de cumplimiento deberá basarse en un análisis de los riesgos a los que está expuesta la empresa. Para la identificación de estos riesgos, han de tenerse en cuenta factores tales como el sector de actividad, la frecuencia, el nivel de interacción de la empresa con competidores o las características del mercado; habiendo siempre de tener en cuenta que el riesgo varía en función del puesto que ocupe cada trabajador.

$\left.2^{\circ}\right)$ Exponer de forma explícita la estrategia: Tan importante como definir bien la estrategia de cumplimiento, es darla a conocer. Es por ello que las estrategias habrán de exponerse preferiblemente por escrito, de forma clara y sencilla y en todas las lenguas que se empleen en la empresa. Estos "manuales", además de describir de forma genérica la legislación de defensa de la competencia de la UE, su finalidad, aplicación o los potenciales costes derivados del incumplimiento, ofrecerán orientaciones para los concretos ámbitos de riesgo.

$3^{\circ}$ ) Compromiso visible y duradero con la estrategia de cumplimiento por parte de la alta dirección: Resulta esencial la implicación de la alta dirección con las políticas de cumplimiento, aconsejándose la designación de un alto directivo como responsable de cumplimiento.

8. La estrategia de cumplimiento ha de ir acompañada de actos formales de reconocimiento por parte del personal y una consideración del esfuerzo de cumplimiento en la evaluación del personal, a través de incentivos y sanciones 5 . La Comisión destaca, también, la importancia de incluir mecanismos adecuados de información interna.

9. Asimismo, incide sobre la importancia de la actualización constante de la estrategia, la habilitación de puntos de contacto, que permitan al trabajador asesorarse, en caso de dudas sobre la compatibilidad de un determinado comportamiento o acuerdo con las normas de la competencia, y la formación adecuada sobre la materia ${ }^{6}$.

\footnotetext{
los programas de cumplimiento en materia de competencia es un reto que "las Autoridades de competencia podrían acometer aprovechando el eco que a buen seguro tendrá su implantación en materia penal".

${ }^{3}$ Comisión EuROPEA, La importancia de cumplir: Qué pueden hacer las compañías para respetar mejor las normas de competencia de la UE, Oficina de Publicaciones de la Unión Europea, Luxemburgo, 2012.

${ }^{4}$ Comisión Europea, La importancia de cumplir... cit., punto 4.1.

${ }^{5}$ Comisión Europea, La importancia de cumplir... cit., punto 4.2.

${ }^{6}$ Comisión Europea, La importancia de cumplir... cit., punto 4.3.
} 
10. Finalmente, entiende que los controles y las auditorías también pueden ser herramientas eficaces para prevenir y detectar comportamientos anticompetitivos dentro de la empresa ${ }^{7}$.

\section{Cómo limitar la exposición de la empresa cuando ya ha fallado la estrategia de cumplimiento}

11. Una estrategia de cumplimiento efectiva debe de evitar que se produzca el incumplimiento, no obstante, siempre cabe la posibilidad de que se produzca la infracción, en cuyo caso, la estrategia serviría para limitar la exposición de la empresa, poniendo fin a la conducta anticompetitiva cuanto antes $\mathrm{y}$, en su caso, cooperando con la autoridad de competencia, en el marco de un programa de clemencia o de un procedimiento de transacción ${ }^{8}$.

La Comisión Europea destaca así la función preventiva de las estrategias de compliance, no reconociendo una función moderadora de la responsabilidad de la empresa infractora9 9 .

\section{Guías sobre compliance en materia de competencia en algunos países de nuestro entorno}

\section{Reino Unido}

\section{A) Introducción}

12. En Reino Unido, la Office of Fair Trading (OFT), en junio de 2011, publica su Guía: How your business can achieve compliance with competition law ${ }^{10}$, que sustituye a su Guía rápida: How Your Business Can Achieve Compliance ${ }^{l 1}$, de 2005. A través de esta nueva guía, la OFT pretende avanzar en la cultura de cumplimiento normativo, ofreciendo a las empresas una pauta dirigida a implementar herramientas de compliance eficaces y premiando sus esfuerzos, en caso de infracción, a la hora de determinar la sanción.

13. Conviene, también, destacar la publicación Drivers of Compliance and Non-compliance with Competition. An OFT report, en mayo de $2010^{12}$, en la que la autoridad de competencia inglesa,

\footnotetext{
${ }^{7}$ Comisión Europea, La importancia de cumplir... cit., punto 4.4.

${ }^{8}$ Sobre el criterio de la Comisión Europea, se muestra muy crítica P. Pérez Fernández, "La importancia de los programas de cumplimiento (compliance programmes) en las políticas sancionadoras de las autoridades de competencia", Revista de Derecho Mercantil, n 292, 2014, apartado III, posición que reitera en P. PÉrez FernándEz, "La importancia de los programas de cumplimiento en las políticas sancionadoras de las autoridades de la competencia”, en L. Arroyo Jiménez y A. Nieto Martín (dirs.), Autorregulación y sanciones, Cizur Menor (Navarra), Aranzadi, 2015.

${ }_{9}^{9}$ Apunta, Y. Martínez Mata, "Los programas de «compliance» en derecho de la competencia", en S. Subirana de la Cruz, y M. Fortuny Cendra (dirs.), Compliance en el sector público, Cizur Menor (Navarra), Aranzadi, 2020, que en los años 80 y 90 sí se dictaron algunas decisiones en las que se valoraron positivamente la implementación de programas de compliance ex post, pero que, a día de hoy, "no tienen ningún impacto, ni positivo ni negativo, en un procedimiento sancionador". En este mismo sentido, J. A. Rodríguez Mínguez, "El reto de la implantación de los PDC en materia antitrust en España", Revista de derecho de la competencia y la distribución, $\mathrm{n}^{\circ}$ 17, 2015; A. Angulo Garzaro, "Los compliance programs en el derecho de la competencia como medida preventiva de futuros procedimientos sancionadores", en X. A. LLUNCH (coord.), Las medidas preventivas de conflictos jurídicos en contextos económicos inestables, Bosch, 2014; o P. Pérez Fernández, "La importancia de los programas de cumplimiento (compliance programmes) en las políticas sancionadoras de las autoridades de competencia", cit., nota a pie de página n. ${ }^{\circ}$ 15. Asimismo, P. J Wils, Wouter., "Antitrust Compliance Programmes \& Optimal Antitrust Enforcement", Journal of Antitrust Enforcement, Volume 1, Issue 1, April 2013, p. 5, disponible en: https://ssrn.com/abstract=2176309, en su nota a pie de página 3, cita siete decisiones, dictadas durante el período entre 1982 y 1992, en las que sí se tuvo en cuenta la existencia de un programa de compliance como elemento moderador de la sanción, a saber: "Decisions of 7 December 1982, National Panasonic, [1982] L 354/28; of 14 December 1984, John Deere, [1985] OJ L 35/58; of 16 December 1985, Sperry New Holland, [1985] OJ L376/21; of 18 December 1987, Fisher-Price/Quaker Oats - Toyco, [1988] OJ L 49/19; of 22 December 1987, Eurofix-Bauco/Hilti, [1988] OJ L65/19; of 18 July 1988, British Sugar, [1988] OJ L 284/41; of 5 June 1991, Viho/ Toshiba, [1991] OJ L 287/39; and of 15 July 1992, Viho/Parker Pen, [1992] OJ L233/27”.

${ }^{10}$ OFT 1341, Guidance: How your business can achieve compliance with competition law, junio de 2011

${ }^{11}$ OFT 424, How Your Business Can Achieve Compliance, 2005

${ }^{12}$ OFT 1227, Drivers of Compliance and Non-compliance with Competition. An OFT report, mayo de 2010
} 
tras el análisis de las actividades de compliance de 22 grandes empresas, pretende comprender mejor los retos prácticos a los que se enfrentan las empresas que tratan de lograr una cultura de cumplimiento, a través de un análisis de los motivos que las mueven a cumplir o incumplir las normas de defensa de la competencia.

14. Asimismo, la OFT publica una guía, bajo el título Company directors and competition law, en junio de $2011^{13}$, con el objetivo de ayudar a los directores de empresas a comprender sus responsabilidades en el marco del Derecho de la Competencia.

15. En el año 2014, la Competition and Markets Authority (CMA), que desde el 2013 reemplaza a la OFT y a la Competition Commission, publica la Quick Guide to Complying with Competition Law $^{14} \mathrm{y}$, más recientemente, la Draf CMA's guidance as to the appropriate amount of a penalty, de 18 de marzo de 2019, en la que recuerda los efectos que las actividades de compliance pueden tener en la cuantificación de la pena, y la actualización de la Guidance: Competition law risk: a short guide, de 10 de septiembre de $2020^{15}$.

16. El número de documentos que aluden de alguna forma a los programas de compliance prueban la importancia que, para la autoridad de competencia inglesa, tiene lograr en el ámbito de las empresas una cultura de cumplimiento en relación con el Derecho de defensa de la competencia.

\section{B) Programas de cumplimiento eficaces}

17. La autoridad de competencia inglesa considera fundamental el compromiso de cumplimiento por parte del personal de alta dirección de la empresa (from de top down), considerando que su compromiso claro e inequívoco con el cumplimiento de las normas de defensa de la competencia resulta fundamental para el éxito del programa de cumplimiento ${ }^{16}$.

18. Partiendo de esta premisa, la OFT plantea un enfoque basado en los riesgos, dividido en cuatro $\operatorname{pasos}^{17}$ :

$1^{\circ}$ ) Identificación de los riesgos: La OFT llama a las empresas a analizar su negocio y a identificar las áreas más expuestas a las infracciones del Derecho de la Competencia. Con frecuencia, tales riesgos dependerán de la naturaleza y el tamaño de la empresa.

La autoridad de competencia inglesa, en la Guía How your business can achieve compliance with competition law, destaca, a modo de ejemplo, algunos de los riesgos potenciales más comunes, con el fin de orientar a las empresas en la implantación de sus actividades de compliance $^{18}$.

$2^{\circ}$ ) Evaluación de los riesgos: Una vez identificados los riesgos, el siguiente paso consiste en determinar su nivel de gravedad. Se recomienda a las empresas clasificarlos como bajos, medios y altos, dejando abierta la posibilidad de emplear otra escala.

Ya evaluados los riesgos, se destaca la conveniencia de clasificar también al personal en función de su exposición (personal de alto riesgo, personal de riesgo medio y personal de

\footnotetext{
${ }^{13}$ OFT 1340, Company directors and competition law, junio de 2011

${ }^{14}$ CMA, Quick Guide to Complying with Competition Law. Protecting businesses and consumers from anti-competitive behaviour, 2014

${ }^{15}$ CMA, Guidance: Competition law risk: a short guide, actualizada el 10 de septiembre de 2020

${ }^{16}$ OFT 1341, Guidance: How your business... cit., 2. Véase, asimismo, OFT 1340, Company directors...cit., donde se insiste en la importancia de este compromiso.

${ }^{17}$ OFT 1341, Guidance: How your business... cit., 1.15 y ss.

${ }^{18}$ Véanse, con detalle, en OFT 1341, Guidance: How your business ... cit., 3.3 (en relación a cárteles), 3.5 (en relación a otros posibles acuerdos anticompetitivos), 3.9 y 3.10 (en relación al abuso de posición de dominio).
} 
riesgo bajo). Por ejemplo, el personal que trata con competidores estaría clasificado como de riesgo alto, sin embargo, el personal de mano de obra, se consideraría de riesgo bajo ${ }^{19}$.

$3^{\circ}$ ) Mitigación de los riesgos: Tras la identificación y evaluación de los riesgos, la empresa ha de implementar actividades de formación, políticas y procedimientos encaminados a la prevención, incluyendo la introducción de medidas disciplinarias internas en caso de incumplimiento.

Se trata de conseguir una efectiva cultura de cumplimiento en materia de competencia, empleando las acciones apropiadas para el tamaño de la empresa y la naturaleza de los riesgos identificados.

$4^{\circ}$ ) Revisión: Por último, las empresas deben de revisar regularmente su plan de cumplimiento normativo, para asegurase de que existe un verdadero compromiso con la política de cumplimiento, así como comprobar que los riesgos identificados o la evaluación de los mismos no han cambiado y que las actividades de mitigación siguen siendo adecuadas y eficaces. Es indudable que, a lo largo de la vida de una empresa, los riesgos pueden cambiar. A modo de ejemplo, indica la OFT cómo el incremento de la cuota de mercado de una empresa puede exponerla a la infracción de las normas sobre abuso de posición de dominio.

No existe un periodo de revisión estándar, sino que es la empresa la que debe decidir la frecuencia de las revisiones. Al margen de las revisiones periódicas, es conveniente la realización de revisiones puntuales, cuando se produzcan circunstancias tales como la apertura de una investigación relativa a las infracciones del Derecho de la Competencia que afecte a la empresa o la apertura del negocio a nuevos mercados.

\section{C) Determinación del importe de la sanción}

19. La OFT, en su Guidance: How your business can achieve compliance with competition law, parte de la premisa de que el principal beneficio que deriva de un programa de cumplimiento eficaz es el de evitar las infracciones de las normas de defensa de la competencia. Por ende, la realización de actividades de compliance no influyen, en un principio, en la determinación de la multa ${ }^{20}$.

20. Si bien es cierto, reconoce, en supuestos concretos, una reducción del importe de la multa de hasta un $10 \%$, si se han implementado las medidas de cumplimiento adecuadas ${ }^{21}$ en materia de competencia ${ }^{22}$, bien sea antes de haberse producido la infracción o de forma inmediata al conocimiento por parte de la empresa de la posible infracción del Derecho de la Competencia ${ }^{23}$.

La concesión de dicha reducción y, en su caso, la determinación de su cuantía, se realizará caso por caso, en función de la adecuación de las medidas de compliance adoptadas. La autoridad de competencia inglesa otorga especial valor a las medidas de cumplimiento adoptadas ex post, considerándolas un "factor relevante" 24 .

21. Como regla general, en caso de infracción, la existencia de un programa de cumplimiento podría considerarse, en principio, una circunstancia agravante, puesto que ello supondría desincentivar la adopción de políticas de cumplimiento ${ }^{25}$. Si bien es cierto, la OFT considera esta posibilidad en

\footnotetext{
${ }^{19}$ Véanse, con detalle, los ejemplos que ofrece la OFT 1341, Guidance: How your business ... cit., en los apartados 4.5 a 4.6.

${ }^{20}$ OFT 1341, Guidance: How your business ... cit., 7.1.

${ }^{21}$ Según la OFT 1341, Guidance: How your business... cit., 7.3, siempre que se pretenda una reducción de este tipo, la empresa habrá de probar que las medidas de compliance adoptadas responden a los pasos descritos, resultando adecuadas para el tamaño de la empresa y su nivel de riesgo.

${ }^{22}$ Medidas dirigidas al cumplimiento de las prohibiciones recogidas en los capítulos I y II de la Competition Act 1998 y los arts.101 y 102 TFUE.

${ }^{23}$ OFT 1341, Guidance: How your business... cit., 7.1.

${ }^{24}$ OFT 1341, Guidance: How your business ... cit., 7.4.

${ }^{25}$ OFT 1227, Drivers of Compliance... cit., 1.14.
} 
situaciones en las que el programa se utilice para facilitar la infracción, para engañar a la autoridad de competencia en cuanto a la existencia de la infracción o para intentar ocultarla ${ }^{26}$.

22. De forma más reciente, en septiembre de 2019, la CMA, en la DrafCMA's guidance as to the appropriate amount of a penalty, reitera este criterio. Recogiendo, entre las circunstancias atenuantes, la adopción de medidas adecuadas para garantizar el cumplimiento de las prohibiciones del capítulo I y del capítulo II de la Competition Act, aludiendo expresamente, a pie de página, a la reducción del $10 \%$ para aquellas empresas infractoras que hubiesen adoptado medidas eficaces de compliance, incluso a la posibilidad excepcional de considerar tales medidas como una circunstancia agravante ${ }^{27}$.

\section{Francia}

\section{A) Introducción}

23. El 16 de mayo de 2011, la Autorité de Defense de la Concurrence (ADC) publica una Comunicación relativa al método de determinación de las sanciones pecuniarias ${ }^{28}$, en la que no hace una especial referencia a la incidencia de los programas de cumplimiento en la individualización de la multa, pero sí anima a las empresas a implementar programas de cumplimiento normativo en materia de competencia y anuncia la próxima publicación de un documento marco sobre el particular ${ }^{29}$.

24. La ADC publica el anunciado Documento marco el 10 de febrero de $2012^{30}$. En él destaca la conveniencia de contar con un programa de cumplimiento eficaz, indica las condiciones que ha de reunir dicho programa para alcanzar tal eficacia y desvela su criterio a la hora valorarlo para la determinación de la multa, particularmente en el marco del procedimiento de non-cotestation des griefs (settlements).

25. Con motivo la reforma del art. 464.2 del Código de Comercio por la Loi $n^{\circ} 2015-990 d u$ pour la croissance, l'activité et l'égalité des chances économiques, de 6 de octubre de 2015, por la que se crea un nuevo procedimiento de transaction, reemplazando al denominado procédure de non-contestation des griefs, la ADC dicta una nueva Comunicación relativa a los procedimientos de transacción y los programas de cumplimiento, el 19 de octubre de $2017^{31}$, que viene a sustituir a la Comunicación de 10 de febrero de 2012 relativa a los procedimientos de non-contestation des griefs ${ }^{32}$. El citado documento anula, también, las referencias que, a este antiguo procedimiento, realizaban la ya mencionada Comunicación sobre al método de determinación de sanciones pecuniarias y el Documento marco ${ }^{33}$.

26. A través de esta nueva Comunicación, la autoridad de competencia francesa se reafirma en la importancia de los programas de cumplimiento normativo y en el protagonismo que deben desempeñar en la gestión diaria de las empresas, especialmente en aquellas de tamaño considerable. No obstante, como se explica más adelante, pierden importancia para la determinación de la multa.

\footnotetext{
${ }^{26}$ OFT 1341, Guidance: How your business ... cit., 7.5.

${ }^{27}$ CMA 73, DrafCMA's guidance as to the appropriate amount of a penalty, 18 de marzo de 2019, p.12 y nota pie de página 30.

${ }^{28} \mathrm{ADC}$, Communiqué de l'Autorité du 16 mai 2011 relatif à la méthode de détermination des sanctions pécuniaires

${ }^{29}$ Así se anuncia en la primera nota a pie de página de ADC, Communiqué de l'Autorité du 16... cit.: " [l]'Autorité encourage les entreprises à se doter de programmes de conformité aux règles de concurrence. "son approche de la conformité fera prochainement l'objet d'un document-cadre destiné à les [les entreprises] aider à assurer l'efficacité de ces programmes. Par ailleurs, les modalités suivant lesquelles l'Autorité peut tenir compte de propositions d'engagements de mise en place de tels programmes présentées dans le cadre de la procédure de non contestation des griefs prévue par le III de l'article L.464-2 du code de commerce, en accordant une réduction de sanction pécuniaire si ces engagements sont pertinents, crédibles et vérifiables, seront précisées dans un communiqué de procédure à ce sujet ».

${ }^{30} \mathrm{ADC}$, Document-cadre du 10 février 2012 sur les programmes de conformité aux règles de la concurrence

${ }^{31} \mathrm{ADC}$, Communiqué du 19 octobre 2017 relatif à la procédure de transaction et aux programmes de conformité

${ }^{32} \mathrm{ADC}$, Communiqué du 10 février 2012 relatif à la non-contestation des griefs

${ }^{33}$ ADC, Document-cadre du 10 février 2012... cit.
} 


\section{B) Programas de cumplimiento eficaces}

27. El Documento marco sobre programas de cumplimiento en materia de competencia enumera una serie de elementos que considera que deben estar siempre presentes en un programa de cumplimiento para que éste sea eficaz ${ }^{34}$. A saber:

$\left.1^{\circ}\right)$ Un compromiso público de la empresa:

La empresa ha de manifestar una posición clara, firme y pública de los órganos de administración y los directivos de la empresa, subrayando la importancia del respeto de las normas de defensa de la competencia y asumiendo el compromiso de cumplir y apoyar el programa, habida cuenta de las importantes consecuencias negativas que podrían derivar del incumplimiento. Dicho compromiso resulta esencial, tanto para la economía y reputación de la propia empresa, como para el mercado y los consumidores.

$2^{\circ}$ ) La designación de un responsable de cumplimiento:

El programa, ha de contener, asimismo, el compromiso de designar a una o varias personas, dentro del seno de la empresa, como encargadas de la puesta en marcha y funcionamiento del programa de complimiento. El responsable de cumplimiento será designado por los órganos de administración o dirección de la empresa, se dedicará de forma exclusiva o, al menos, significativa a la gestión del programa, accederá directamente a los órganos de administración de la empresa para informarles sobre su correcta aplicación, contará con los poderes oportunos para garantizar su aplicación efectiva y habrá de contar con los recursos humanos y financieros necesarios, en atención al tamaño y características de la empresa.

$\left.3^{\circ}\right)$ El compromiso de implementar medidas eficaces de información, formación y sensibilización: Este compromiso comporta el diseño y difusión entre los empleados de la empresa de materiales explicativos sobre el significado y el alcance de las normas de competencia, la importancia que su cumplimiento tiene tanto para la empresa como para cada uno de ellos, a título personal, y los mecanismos internos para obtener asesoramiento o advertir de las infracciones reales o potenciales.

Asimismo, habrán de habilitarse herramientas de comunicación interna sobre la existencia y la finalidad del programa de cumplimiento.

El Documento marco incide, también, en la importancia de la formación. Considera necesarias, en primer lugar, una formación regular y obligatoria para todos los empleados, en atención a los riesgos a los que se ven expuestos en función de las tareas que desempeñan, $\mathrm{y}$, en segundo lugar, formaciones puntuales en atención a casos particulares, como puede ser una nueva contratación.

La ADC cree conveniente extender la información relativa a la existencia y finalidad del programa de cumplimiento a los principales socios comerciales y, en su caso, a los accionistas.

$4^{\circ}$ ) El compromiso de implementar mecanismos efectivos de control, auditoría y alerta:

La empresa ha de implementar mecanismos internos para solicitar asesoramiento al responsable del programa sobre cuestiones relativas al cumplimiento de las normas de competencia y, en su caso, denunciar la comisión de una infracción, garantizando el anonimato y la ausencia de represalias.

Además, habrá de realizar evaluaciones periódicas de los distintos aspectos del programa de cumplimiento, pudiendo resultar necesario acudir a terceros.

$\left.5^{\circ}\right)$ El compromiso de implementar un dispositivo efectivo de seguimiento.

Dichos dispositivos han de incluir un procedimiento de tramitación de las solicitudes de asesoramiento, de examen de las alertas y de análisis de las medidas de seguimiento; así como una escala de sanciones para los infractores, que pueda contemplar incluso el despido o la destitución de un cargo empresarial. También podría considerarse la aprobación de un

${ }^{34}$ Para más detalles, véase el epígrafe III del ADC, Document-cadre du 10 février $2012 \ldots$ cit. 
sistema de incentivos que premie al infractor que colabora en el marco del programa con una exención total o parcial de la sanción disciplinaria.

28. La autoridad de competencia francesa advierte que la simple concurrencia de estos cinco elementos no justifica per se la eficacia del programa de cumplimiento, habiendo de examinarse caso por caso su idoneidad. No existe un programa de cumplimiento tipo, sino que estos habrán de contemplar los concretos riesgos a los que las empresas se encuentran expuestas, así como adaptarse a sus características particulares (su naturaleza, su tamaño, el mercado en el que actúa, su forma de organización...).

\section{C) Determinación del importe de la sanción}

29. Según la ADC, un programa de cumplimiento eficaz ha de perseguir dos objetivos: En primer lugar, el de evitar la infracción y, en segundo lugar, cuando el primero no se haya logrado, el de detectar de forma temprana una conducta ilícita ${ }^{35}$.

30. La autoridad de competencia francesa, en el ya citado Documento marco de 2012, reconocía que la existencia de un programa de cumplimiento puede facilitar la participación en un programa de clemencia y, en consecuencia, la obtención del beneficio de la exención o la reducción del importe de la multa, sin embargo, dicho beneficio excluía cualquier otra reducción de la sanción, que pudiera acordarse en función de la existencia del programa de cumplimiento ${ }^{36}$.

31. Asimismo, la ADC entendía que, si no se había presentado solicitud de clemencia o no se reunían los requisitos para poder hacerlo, tampoco se justificaba que la existencia de un programa de cumplimiento fuese valorada para la determinación de la sanción. Por ende, en estos casos, la implementación de un programa de cumplimiento eficaz, anterior a la infracción (programa de cumplimiento ex ante), no se tenía en cuenta como atenuante, dado que su mera existencia no altera la realidad de la infracción, ni la gravedad y la importancia del daño que se haya podido causar; pero tampoco podía considerarse una agravante, incluso en aquellos casos en los que quedase probada la participación de los administradores sociales o directivos de la empresa en la infracción, obviando el compromiso adoptado en el programa de cumplimiento ${ }^{37}$.

32. Si bien es cierto, en el marco del derogado procedimiento de non-contestation des griefs, la ADC sí tenía en cuenta, como elemento moderador de la sanción, el compromiso sustancial, serio y verificable de implementar un programa de cumplimiento eficaz o mejorar aquél con el que ya contaba la empresa. En estos casos, con independencia de la reducción derivada de no presentar alegaciones frente al pliego de cargos, la autoridad de competencia se comprometía a acordar una reducción de hasta un $10 \%$ de la multa. A esta reducción podían sumarse otras, como resultado de la adopción de compromisos adicionales en el marco del procedimiento de non-contestation des griefs, no pemitiéndose nunca superar el límite del $25 \%{ }^{38}$.

33. Sin embargo, con motivo de la aprobación del nuevo procedimiento de transaction, la autoridad de competencia francesa, en su Comunicación relativa a los procedimientos de transacción y los programas de cumplimiento de 2017, aclara que el objeto de los programas de compliance en materia de competencia no ha de ser nunca el de justificar, en su caso, una atenuación de la sanción, especialmente

\footnotetext{
${ }^{35}$ ADC, Document-cadre du 10 février 2012... cit., punto 11.

${ }^{36}$ ADC, Document-cadre du 10 février 2012... cit., punto 27.

${ }^{37}$ ADC, Document-cadre du 10 février 2012... cit., puntos 24-26.

${ }^{38}$ ADC, Document-cadre du 10 février 2012 ... cit., puntos 29-31, en relación con la ADC, Communiqué du 10 février 2012 relatif à la non-contestation des griefs.
} 
cuando se trata de infracciones particularmente graves, como los acuerdos e intercambios de información sobre precios futuros y política comercial ${ }^{39}$.

\section{Italia}

\section{A) Introducción}

34. La Autorità Garante della Concorrenza e del Mercato (AGCM), en relación a los criterios de determinación de la sanción, publica la Linee Guida sulla modalità di applicazione dei criteri di quantificazione delle sanzioni amministrative pecuniarie irrogate dall'Autorità in applicazione dell'art. 15, comma 1, della legge n. 287/90, de 22 de octubre de 2014, n. 25152, considerando, entre las circunstancias atenuantes, la adopción y cumplimiento de un programa de compliance en materia de defensa de la competencia, adecuado y en línea con las mejores prácticas europeas y nacionales ${ }^{40}$.

35. Cuatro años después, la AGCM publica una nueva guía, Linee Guida Sulla Compliance Antitrust, de 25 de septiembre de 2018, que actualiza el parecer de la autoridad de competencia italiana en relación a tales proyectos de cumplimiento, con el fin de promover una cultura de la competencia, prevenir infracciones, alcanzar la seguridad jurídica, en cuanto a los criterios de evaluación de los programas de cumplimiento a los efectos de la atenuación, y articular un sistema de incentivos coherente con los programas de clemencia ${ }^{41}$.

\section{B) Programas de cumplimiento eficaces}

36. La autoridad de competencia italiana entiende que un programa de cumplimiento adecuado, en línea con las mejores prácticas europeas y nacionales, ha de contener los siguientes elementos ${ }^{42}$ :

$\left.1^{\circ}\right)$ El cumplimiento de las normas de defensa de la competencia como parte integrante de la cultura y la política de la empresa:

Un programa de cumplimiento normativo eficaz requiere un claro reconocimiento del valor del respeto hacia las normas de defensa de la competencia como parte integrante de la cultura y la política de la empresa.

La AGCM entiende que ello implica dedicar los recursos suficientes a la aplicación del programa y proporcionar al responsable del programa autonomía e independencia, así como los recursos adecuados.

Este compromiso de la empresa puede materializarse en un reconocimiento expreso a través códigos éticos o de buena conducta, así como en la elaboración de un programa de cumplimiento normativo específico, destinado expresamente a garantizar el cumplimiento de las normas de defensa de competencia.

${ }^{39}$ ADC, Communiqué du 19 octobre 2017... cit., reflejando lo dispuesto en el punto 464 de la Décision $n^{\circ} 17-D-20$ du 18 octobre 2012 relative à des pratiques dans le secteur des revêtements de sols résilients. Conviene recordar que esta comunicación "deroga" el Document-cadre du 10 février 2012 ... cit.

${ }^{40} \mathrm{AGCM}$, Linee Guida sulla modalità di applicazione dei criteri di quantificazione delle sanzioni amministrative pecuniarie irrogate dall'Autorità in applicazione dell'art. 15, comma 1, della legge n. 287/90, de 22 de octubre de 2014, n. 25152, párrafo 23: "l'adozione e il rispetto di uno specifico programma di compliance, adeguato e in linea con le best practice europee e nazionali. La mera esistenza di un programma di compliance non sarà considerata di per sé una circostanza attenuante, in assenza della dimostrazione di un effettivo e concreto impegno al rispetto di quanto previsto nello stesso programma (attraverso, ad esempio, un pieno coinvolgimento del management, l'identificazione del personale responsabile del programma, l'identificazione e valutazione dei rischi sulla base del settore di attività e del contesto operativo, l'organizzazione di attività di training adeguate alle dimensioni economiche dell'impresa, la previsione di incentivi per il rispetto del programma nonché di disincentivi per il mancato rispetto dello stesso, l'implementazione di sistemi di monitoraggio e auditing)".

${ }^{41}$ AGCM, Linee Guida Sulla Compliance Antitrust, de 25 de septiembre de 2018, punto 3.

${ }^{42}$ Con más detalle, consúltese la AGCM, Linee Guida Sulla Compliance... cit., puntos 7-16. 
$2^{\circ}$ ) Identificación y evaluación del riesgo antitrust específico de la empresa:

El programa de cumplimiento debe desarrollarse sobre la base de un análisis cuidadoso del riesgo al que se enfrenta la empresa de incurrir en una conducta anticompetitiva ("riesgo antitrust"). El análisis de los riesgos permite identificar las prioridades de intervención, mediante la identificación de las áreas más expuestas, y las actividades de prevención más adecuadas.

En opinión de la AGCM, la adecuación del programa de cumplimiento a los riesgos específicos de la empresa es un elemento clave a la hora de valorar su eficacia a efectos de ser considerado una circunstancia atenuante, puesto que, en última instancia, la eficacia del programa depende de su capacidad para prevenir y gestionar los riesgos antitrust, con el fin de minimizarlos o eliminarlos por completo.

$3^{\circ}$ ) Actividades de formación y know-how:

El programa debe de prever una formación adecuada al tamaño y al contexto de la empresa, acorde a los riesgos antitrust a los que está expuesta.

En aras de lograr una cultura de cumplimiento, los trabajadores, principalmente aquellos más expuestos al riesgo, deben de recibir una formación periódica, mediante cursos, manuales $o$ guías, acorde a las necesidades específicas de la empresa.

4) Procedimientos de gestión del riesgo antitrust:

En atención a las características de la empresa y al contexto en el que opera, un programa de cumplimiento eficaz debe incluir procedimientos internos de gestión del riesgo antitrust, configurándose dichos mecanismos como una parte de la actividad normal de la empresa ${ }^{43}$.

$5^{\circ}$ ) Sistema de incentivos:

El programa debe de contemplar un sistema adecuado de medidas disciplinarias e incentivos diseñados para garantizar su cumplimiento ${ }^{44}$.

$6^{\circ}$ ) Auditoría y mejora continua del programa:

Un programa de cumplimiento creíble no puede ser una actividad puntual, sino que requiere de un seguimiento periódico y, en su caso, de actualización. Sin perjuicio de la necesaria verificación periódica del programa de cumplimiento, la AGCM pone el énfasis en la importancia de la revisión del programa cuando se produzcan cambios en la actividad empresarial o en el contexto en el que se opera.

\section{C) Determinación del importe de la sanción}

37. La AGCM considera que la existencia de un programa de cumplimiento normativo eficaz puede ser considerada una circunstancia atenuante, reconociendo tal eficacia, no solo a los programas ex ante, sino también a aquellos aprobados con posterioridad al inicio del procedimiento administrativo sancionador (programas ex post o programas ex novo, término, este último, utilizado por la autoridad de competencia italiana).

Tratamiento de los programas ex ante:

38. Con respecto a los programas de cumplimiento implementados antes del inicio de la instrucción del procedimiento sancionador, la AGCM distingue entre si la empresa cuenta con un programa eficaz, con un programa manifiestamente inadecuado o con un programa no manifiestamente inadecuado.

\footnotetext{
${ }^{43}$ La AGCM, Linee Guida Sulla Compliance... cit., punto 13, destaca, entre tales procedimientos, mecanismos para la solicitud de información o asesoramiento, canales de denuncia que garanticen el anonimato del denunciante, auditorías internas, investigaciones periódicas, asesoramiento jurídico de terceros, etc.

${ }^{44}$ La AGCM, Linee Guida Sulla Compliance... cit., punto 14, entiende especialmente relevante prever incentivos para el responsable del control del programa, con ánimo de que encuentre motivación a la hora de garantizar el pleno funcionamiento y la eficacia del programa.
} 
Si la empresa cuenta con un programa de cumplimiento adecuado, que haya mostrado ser una herramienta eficaz para la rápida detección e interrupción de la infracción antes de la apertura de la instrucción del procedimiento, el importe de la multa podrá verse reducido hasta el $15 \%$. No obstante, en aquellos casos en los que la empresa pueda acogerse a un programa de clemencia, esta reducción solo podrá concederse si ha presentado una solicitud de clemencia ${ }^{45}$.

Si la empresa cuenta con un programa manifiestamente inadecuado, la AGCM prevé una posible reducción del importe de la multa de hasta el 5\%, siempre y cuando introduzca cambios sustanciales en el programa después de la apertura de la instrucción del procedimiento (dentro del plazo de seis meses a contar desde la notificación de la apertura de la instrucción).

Si la empresa cuenta con un programa que no resulte manifiestamente inadecuado, la AGCM prevé una posible reducción de hasta el 10\% del importe, siempre y cuando modifique de manera adecuada el programa después de la apertura de la instrucción del procedimiento (dentro del plazo de seis meses a contar desde la notificación de la apertura de la instrucción).

Tratamiento de los programas ex novo ${ }^{46}$ :

39. Salvo en casos excepcionales, la implementación de un programa de cumplimiento ex novo -aprobado después de la apertura de la instrucción del procedimiento- no podrá dar lugar a una reducción de la multa superior al 5\%.

\section{Programas de compliance en relación con la defensa de la competencia en España}

\section{Los programas de compliance en relación con la defensa de la competencia antes de la Guía de la CNMC}

40. Antes de la publicación de la Guía de programas de cumplimiento en relación con la defensa de la competencia, de 10 de junio de 2020, la CNMC ya valoraba positivamente, tanto la existencia de programas de cumplimiento ex ante, como la implementación de programas de cumplimiento ex $\operatorname{post}^{47}$. No obstante, la CNMC, siguiendo el criterio del TJUE en su Sentencia de 18 de julio de 2013 (asunto C-501/11 Schindler Holding y otros/Comisión), entiende que la mera existencia de un programa no puede considerarse, sin más, como una circunstancia atenuante a efectos de determinación de la sanción ${ }^{48}$.

41. Entre las Resoluciones de la CNMC, es difícil encontrar ejemplos en los que el programa reúna las condiciones oportunas para ser tenidos en cuenta como una circunstancia atenuante al amparo del art. 64 de la LDC.

\footnotetext{
${ }^{45}$ Este vínculo con la participación en un programa de clemencia ha sido comentado ampliamente por F. C. GuIDO GHEZZI, "The Italian guidelines on antitrust compliance and the difficult goal of matching deterrence, education, and business ethics", Bocconi Legal Studies Research Paper, No. 3381638, May 2019, disponible en: https://ssrn.com/abstract=3381638, pp. 17-21.

${ }^{46}$ AGCM, Linee Guida Sulla Compliance... cit., punto 27.

${ }^{47}$ Aunque ya nos hemos referido a estos conceptos, en atención a la valoración que de estos programas de cumplimiento hacen otras autoridades de competencia, conviene aclarar que, tal y como expresa la CNMC en su Guía sobre los programas de cumplimiento en relación con las normas de defensa de la competencia, de 10 de junio de 2020, pp. 6, 13 y 14, un programa de cumplimiento ex ante es aquél con el que cuenta la empresa "con anterioridad al inicio del procedimiento administrativo sancionador por la CNMC", mientras que un programa de cumplimiento ex post es aquel que la empresa implementa o modifica para su mejora una vez que la empresa ya ha sido investigada.

${ }^{48}$ La STJUE 18 de julio de 2013, C-501/11, Schindler Holding y otros/Comisión, ECLI:EU:C:2013:522, respecto la eficacia del "programa de adecuación" establecido por el Grupo Schindler, llega a afirmar que no solo "no surtió efecto positivo sino que, por el contrario, dificultó el descubrimiento de las infracciones".
} 
42. En relación a los programas de cumplimiento ex ante, la propia Guía reconoce que, hasta el momento, los programas analizados "no reunían los elementos suficientes para atenuar la responsabilidad de las empresas imputadas"49.

Así, por ejemplo, la Resolución de la CNMC de 23 de julio, en el expediente S/0482/13, Fabricantes de Automóviles, considera ineficaz el programa de cumplimiento analizado, puesto que no articula y aplica, efectivamente, "controles internos y severas sanciones disciplinarias por incumplimiento". En muy parecidos términos, la Resolución de 8 de junio de 2017, en el expediente S/DC/0557/15, Nokia, afirma que, cuando los hechos acreditados no permiten concluir la existencia previa a la infracción de un programa de cumplimiento eficaz, "no cabe deducir el genuino compromiso de la empresa de que se trate con la observancia de la normativa de competencia, a los efectos de valorarlo como atenuante". Los mismos argumentos adopta la Resolución de 26 de julio de 2018, en el expediente S/DC/0565/15, Licitaciones informáticas, para valorar las acciones de compliance alegadas por EVERIS.

43. Asimismo, la CNMC siempre ha hecho una valoración positiva de los programas de cumplimiento ex post y, en determinados casos, llegó a considerarlos como un elemento moderador de la sanción.

Por ejemplo, en la Resolución de la CNMC de 17 de septiembre de 2015, en el expediente SNC/0036/15, Mediaset, se acogen favorablemente las medidas reparadoras adoptadas por MEDIASET, entre ellas, la implementación de un programa de cumplimiento que, si bien no acepta como circunstancia atenuante, sí entiende que puede ser tenido en cuenta como elemento moderador de la sanción.

A esta función de elemento moderador, hace referencia también la Resolución de la CNMC de 6 de septiembre de 2016, en el expediente S/DC/0544/15, Mudanzas Internacionales. AGS, una de las empresas partícipes del cártel, solicita que su programa de cumplimiento ex post sea valorado como una circunstancia atenuante, fundamentando su pretensión en la aplicación analógica de la previsión del art. 31 quater del Código Penal, en la que se contempla que la existencia de un programa de compliance, implantado antes del comienzo del juicio oral, puede ser considerado como una circunstancia atenuante de responsabilidad de la persona jurídica. La CNMC entiende que no ha lugar a una aplicación analógica de las garantías del Derecho penal en el ámbito del Derecho administrativo sancionador, aunque reconoce, en abstracto, la posibilidad de que un programa de cumplimiento ex post pueda ser tenido en cuenta para modular la sanción. Además, aunque considera positivas este tipo de actuaciones, entiende que del contenido del programa de compliance presentado no puede inferirse una aplicación eficaz. En este mismo sentido, la CNMC, en su Resolución de 1 de octubre de 2019, en el expediente S/DC/0612/17, Montaje y Mantenimiento Industrial, se pronuncia acerca de los programas de cumplimiento normativo ex post presentados por PREMONOR y TMS.

44. En otro orden de cosas, la Ley $9 / 2017$, de 8 de noviembre, de Contratos del Sector Público, por la que se transponen al ordenamiento jurídico español las Directivas del Parlamento Europeo y del Consejo 2014/23/UE y 2014/24/UE, de 26 de febrero de 2014 (LCSP), en su art. 71. b), prohíbe contratar con el sector público a todas las empresas sancionadas con carácter firme por infracción grave en materia de "falseamiento de la competencia". No obstante, el art. 72.5 LCSP, prevé la posibilidad de eludir dicha prohibición, a aquellas empresas que acrediten el pago o compromiso de pago de las multas e indemnizaciones y adopten medidas de compliance apropiadas ${ }^{50}$.

\footnotetext{
${ }^{49}$ Encontramos alguna resolución aislada, como la Resolución de la CNMC, de 29 de octubre de 2019, en el expediente S/0629/18, Asistencia Técnica Vaillant, en la que, sin mucha más explicación en relación al programa de compliance, se aprecia "la existencia de atenuantes que fundamentalmente se centran en la existencia de una colaboración con la autoridad y la implantación de un programa de comunicación dentro del programa de compliance de las empresas".

${ }^{50}$ En concreto, el art. 72.5 LCSP dispone que "la persona incursa en la causa de prohibición acredite el pago o compromiso de pago de las multas e indemnizaciones fijadas por sentencia o resolución administrativa de las que se derive la causa de prohibición de contratar, siempre y cuando las citadas personas hayan sido declaradas responsables del pago de la misma en la citada sentencia o resolución, y la adopción de medidas técnicas, organizativas y de personal apropiadas para evitar la comisión de futuras infracciones administrativas, entre las que quedará incluido el acogerse al programa de clemencia en materia de falseamiento de la competencia".
} 


\section{Guía de la CNMC de programas de compliance en relación con la defensa de la competencia}

\section{A) Introducción}

45. La publicación de la Guía de la CNMC de programas de cumplimiento en relación con la defensa de la competencia, de 10 de junio de 2020, supone un importante impulso de las políticas de compliance en este campo ${ }^{51}$.

46. La Guía concreta pormenorizadamente los requisitos que ha de reunir un programa de cumplimiento normativo para ser considerado eficaz, tanto para prevenir la participación en infracciones de la competencia, como para detectar y reaccionar de forma temprana, cuando no se hayan podido evitar.

47. Además, la CNMC define las consecuencias que derivan de la implantación de un programa efectivo, ya sea ex ante o ex post, en los expedientes abiertos por la CNMC, reconociendo la posibilidad de que sean considerados elemento moderador de la sanción o, incluso, exonerador del pago de la multa.

\section{B) Programas de cumplimento eficaz según el criterio de la CNMC}

48. La CNMC, en su Guía de programas de cumplimiento en relación con la defensa de la competencia, señala que para considerar un programa de cumplimiento como eficaz ha de cumplir con una serie de requisitos ${ }^{52}$ :

$\left.1^{\circ}\right)$ Implicación de los órganos de administración y/o los principales directivos de la empresa: Un programa de cumplimiento requiere la implicación de los principales directivos, ya que su conducta es reflejo de las políticas de la empresa y de su cultura de trabajo.

La CNMC considera, incluso, que la participación directa de alguno de los directivos en una infracción muy grave de la LDC podría determinar, en función de las concretas circunstancias del caso, el carácter ineficaz del programa de cumplimiento normativo, si se concluye que la participación en la infracción supone la exclusión del compromiso verdadero con el respeto a las normas de defensa de la competencia.

$\left.2^{\circ}\right)$ Formación eficaz:

Tal y como afirma la CNMC, "otro de los pilares básicos de cualquier programa de cumplimiento es la formación de los trabajadores de la compañía, adaptada en cada caso a su ámbito y funciones".

Además de programar una formación regular, la empresa debe prever "sesiones de formación ad hoc" cuando se produzcan cambios que puedan implicar un riesgo, tales como una modificación accionarial o de control, un nuevo proveedor, un nuevo mercado, etc.

Una formación adecuada es esencial para que el resto de los elementos del programa de cumplimiento puedan alcanzar eficacia (por ejemplo, el canal de denuncias no serviría para su cometido, los riesgos no podrían identificarse adecuadamente, etc.).

$3^{\circ}$ ) Existencia de un canal de denuncias:

Los canales de denuncia interna son un instrumento esencial para la implementación eficaz y la gestión de los programas de cumplimiento. Estos permiten detectar con rapidez las conductas infractoras y, por ende, disuadir de su comisión a trabajadores y directivos. Obvia-

\footnotetext{
${ }^{51}$ En este sentido, J. Suderow, "Compliance y Libre Competencia. Guía de la CNMC y mejores prácticas nacionales e internacionales", Aranzadi digital, n ${ }^{\circ}$ 1, 2020: "La Guía supone un gran avance, ya que la CNMC determina de forma anticipada los criterios que empleará a la hora de evaluar un programa de cumplimiento, ya sea para modular una posible sanción o para imponer o levantar una prohibición de contratar".

${ }^{52}$ Con más detalle, en CNMC, Guía sobre los programas... cit., pp. 8-13. En relación a los elementos a valorar para determinar la concurrencia de un determinado requisito, véase su Anexo, pp. 17-21.
} 
mente, deben siempre garantizar el anonimato del denunciante con el fin de evitar posibles represalias.

El impulso definitivo para estos canales de denuncias viene dado por la Directiva de protección de informantes (Directiva Whistleblowing ${ }^{53}$ ), de 23 de octubre de 2019, que impone la obligación de instaurar un canal de denuncias en empresas de más de 50 trabajadores, siendo fundamental que abarque las infracciones de las normas de defensa de la competencia. En este sentido, el art. 2 de la Directiva, sobre su ámbito material, hace alusión expresa a las "infracciones relativas al mercado interior, tal como se contemplan en el artículo 26, apartado 2, del TFUE, incluidas las infracciones de las normas de la Unión en materia de competencia y ayudas otorgadas por los Estados".

$\left.4^{\circ}\right)$ Independencia y autonomía del responsable del diseño y control de las políticas de cumplimiento:

Es necesario también que exista un responsable de diseño y control de las políticas de cumplimiento independiente y autónomo (el responsable de cumplimiento), que reporte directamente al órgano de administración y cuente con los recursos necesarios en función del tamaño y características de la empresa.

$\left.5^{\circ}\right)$ Identificación de riesgos y diseño de protocolos o mecanismos de control:

Un programa de cumplimiento eficaz debería poder evaluar -identificar, analizar y valorarlos riesgos a los que la empresa se encuentra expuesta. Un mapa de riesgos debe de identificar: las áreas de negocio, procesos de negocio y personas más expuestas; la probabilidad de que la infracción llegue a materializarse; y el impacto de la infracción sobre la empresa y su personal (sanciones, reputación, prohibiciones de contratar con la administración pública, indemnizaciones, costes legales, etc.). Contando con un buen mapa de riesgos es posible diseñar protocolos y mecanismos de detección temprana de esos riesgos, minimizando su materialización.

$6^{\circ}$ ) Diseño del procedimiento interno para la gestión de denuncias y la gestión de la detección de infracciones:

El programa de cumplimiento debe de incluir procedimientos internos para la gestión de denuncias y la gestión de la detección de infracciones, esto es, mecanismos que permitan solicitar asesoramiento en relación con una práctica y advertir sobre la existencia de sospechas o constatación de infracciones.

$7^{\circ}$ ) Diseño de un sistema disciplinario transparente y eficaz:

El programa ha de contemplar medidas disciplinarias para el incumplidor, tales como la reducción de ingresos, su merma de posibilidades de promoción o, incluso, su despido.

Asimismo, podría incluir un sistema de incentivos para el cumplidor o aquel que colabore en el marco del programa.

La CNMC valora de forma positiva la inclusión en los contratos de alta dirección de cláusulas de rescisión por la constatación de la comisión de infracciones de la Ley de Defensa de la Competencia.

\section{C) Consecuencias derivadas de la implantación de un programa de cumplimiento eficaz en los expedientes abiertos por la CNMC}

49. La CNMC entiende que la implantación de un programa de cumplimiento eficaz, ex ante o ex post, puede justificar una atenuación de la responsabilidad y, por ende, considerarse como un elemento moderador de la sanción. La autoridad de competencia muestra preferencia por los programas de cumplimiento ex ante frente a las medidas de compliance adoptadas después de la incoación del procedimiento sancionador, sin por ello dejar de valorarlas de forma positiva.

${ }^{53}$ La Directiva (UE) 2019/1937 del Parlamento Europeo y del Consejo, de 23 de octubre de 2019, relativa a la protección de las personas que informen sobre infracciones del Derecho de la Unión 
50. Partiendo de esta diferencia entre programas de cumplimiento ex ante y ex post, la CNMC se compromete a lo siguiente ${ }^{54}$ :

\section{a) En relación con los programas de cumplimiento ex ante}

51. En aquellos casos en los que la empresa cuenta con un programa de cumplimiento con anterioridad al inicio del procedimiento sancionador, la CNMC diferencia dos situaciones: supuestos de infracción muy grave constitutiva de cártel y supuestos de infracción grave o muy grave no constitutiva de cártel.

52. En caso de infracción muy grave constitutiva de cártel, la CNMC distingue entre si la empresa se ha acogido o no a un programa de clemencia.

Si la empresa se ha acogido a un programa de clemencia, además de los beneficios derivados de los arts. 65 y 66 de la LDC (sobre exención y reducción del pago de multas, respectivamente), la existencia del programa de cumplimiento podrá tenerse en cuenta como circunstancia atenuante.

No obstante, en el caso de no participar en un programa de clemencia, la existencia de un programa de cumplimiento, unida a su colaboración activa y eficaz con la CNMC y al reconocimiento de los hechos, podrá derivar, asimismo, en una atenuación de la responsabilidad y en la consiguiente reducción de la sanción.

53. En los supuestos de infracción grave o muy grave, pero no constitutiva de cártel, la CNMC distingue entre si la empresa ha colaborado o no en la detección e investigación de la infracción.

Si la empresa, gracias a un programa de cumplimiento eficaz, ha colaborado en la detección e investigación de la infracción, verá reflejada en la resolución sancionadora la atenuación de su responsabilidad, con la consiguiente reducción de la multa, pudiendo incluso considerarse la exoneración del pago.

En los supuestos de infracción grave o muy grave, no constitutiva de cártel, la empresa que no ha colaborado con la detección e investigación, también podrá ver atenuada su responsabilidad en la infracción, siempre que muestre su compromiso con el cumplimiento de las normas de defensa de la competencia. La CNMC entiende que existe tal compromiso cuando se reconozcan los hechos detectados, se ponga fin a la conducta infractora y se adopten decisiones, de forma rápida y voluntaria, que remedien los perjuicios de la misma para la competencia.

\section{b) En relación con los programas de cumplimiento ex post}

54. Pese a mostrar la CNMC una preferencia por los programas ex ante, los programas de cumplimiento elaborados ex post también podrán valorarse para la modulación de la sanción que eventualmente pudiera corresponderle a la empresa conforme a la atenuación de su responsabilidad derivada del programa.

55. La CNMC permite a la empresa infractora, una vez detectada la infracción e iniciado el procedimiento administrativo sancionador, presentar un proyecto de diseño de programa de cumplimiento a la Dirección de Competencia lo antes posible, en todo caso, antes de la notificación de la propuesta de resolución. Nuestra autoridad de competencia valorará si el programa, acompañado del reconocimiento de los hechos y de la colaboración activa y eficaz de la empresa, puede traducirse en una atenuación de la responsabilidad y, en consecuencia, considerarse para determinar una posible modulación de la sanción.

\footnotetext{
${ }^{54}$ Con más detalle, CNMC, Guía sobre los programas... cit., pp. 13-16. Si bien es cierto que la Guía hace también una somera -y algo imprecisa- referencia a la valoración de los programas ex ante y ex post para determinar la aplicación de las medidas correctoras previstas en el art. 72.5 LCSP, para guardar el paralelismo con el análisis de las Guías extranjeras analizadas, nos centraremos únicamente en el estudio de los efectos que un programa de compliance eficaz puede llegar a tener sobre la determinación de la sanción.
} 


\section{La aplicación de las previsiones de la Guía de la CNMC: Resolución de la CNMC de 11 de mayo de 2021, en el expediente S/DC/0627/18, Consultoras}

56. La Resolución de la CNMC de 11 de mayo de 2021, en el expediente S/DC/0627/18, Consultoras, multa con un total de 6,3 millones de Euros a 22 empresas de servicios de consultoría y a varios de sus directivos por incurrir en una infracción constitutiva de cártel. Las empresas distribuidas en dos redes de colaboración (norte y nacional) formaron dos cárteles diferenciados para manipular las licitaciones públicas durante al menos 10 años (2008-2018). Este tipo de conductas son consideradas por la CNMC como especialmente dañinas, al tener un impacto adicional en los fondos públicos.

57. En el marco de este expediente sancionatorio, son tres las empresas -INDRA, DELOITTE y KPMG- que alegan haber implementado programas de cumplimiento, ex ante o ex post, y consideran que cumplen los requisitos para la aplicación de los incentivos recogidos en la Guía de la CNMC.

58. INDRA puso de manifiesto la adopción de medidas de compliance tanto anteriores como posteriores a la incoación del expediente.

Medidas ex ante:

INDRA disponía, desde el año 2001, de un Código de Cumplimiento Ético y Legal que, desde 2015, incluye un apartado específico dedicado a la "protección de la competencia". En ese mismo año, se puso en marcha un programa de formación en materia de competencia, adaptado a su negocio y actividad, dirigido a erradicar y prevenir infracciones.

Medidas ex post:

Con posterioridad a la incoación del expediente, INDRA, en octubre de 2019, adoptó un Manual de prevención de riesgos en Derecho de la Competencia, que responde adecuadamente a los requisitos que la Guía de la CNMC exige para que las acciones de compliance puedan ser consideradas eficaces: implicación de la alta dirección de la empresa con el cumplimiento del programa, identificación de los riesgos, protocolo de actuación de la Unidad de Cumplimiento, un canal de denuncias, obligatoriedad de los cursos de formación, etc.

59. En relación con el expediente analizado, INDRA puso en marcha una investigación interna en la empresa, detectando la existencia de la conducta imputada por la CNMC, así como la documentación que la acreditaba -que se aportó como prueba al expediente-, y la participación de dos directivos, que fueron objeto de un despido disciplinario.

60. INDRA, como consecuencia del reconocimiento de su participación en la infracción y su colaboración activa con la autoridad de competencia, solicita que se reduzca su multa en un porcentaje de, al menos, el 30\%. La CNMC valora positivamente las medidas de cumplimiento, adoptadas ex ante y ex post, considerando que cumplen las exigencias para poder ser consideradas como circunstancia atenuante, concediendo una reducción del $10 \%$ de la multa ${ }^{55}$ (art. 64.3 de la LDC, en relación con la Guía de la CNMC)._

61. Por su parte, KPMG y DELOITTE contaban, antes de la incoación del expediente, con un Código de conducta, que abarcaba el cumplimiento de las normas de competencia, pero carecía de pro-

${ }^{55}$ Del tenor literal de la Resolución de la CNMC de 11 de mayo de 2021, en el expediente S/DC/0627/18, Consultoras, se deduce que se han valorado principalmente las medidas adoptadas ex post, cuando afirma "conceder una reducción del 10\% de la multa a INDRA BUSINESS CONSULTING al apreciar la adecuación de las medidas reactivas incluidas en su programa de cumplimiento en aras de su eficacia, como son acciones formativas especializadas, medidas disciplinarias, colaboración activa y eficaz durante el procedimiento y el reconocimiento de los hechos". 
cedimientos de control. Estas empresas también adoptaron medidas ex post, presentando proyectos de mejora.

62. No obstante, los "esfuerzos" de sendas consultoras no resultan, a los ojos de la CNMC, merecedores de ser considerados una circunstancia atenuante. En primer lugar, porque los programas de cumplimiento no son específicos para las normas de defensa de competencia; además, las empresas no cuentan con programas ex ante adecuados y, de las medidas ex post, no puede deducirse la adopción de políticas de cumplimiento verdaderamente efectivas; y tampoco se adoptan medidas reactivas firmes, dirigidas a evitar la repetición de este tipo de comportamientos.

\section{Consideraciones finales}

63. Todas las Guías analizadas están de acuerdo en los requisitos que ha de cumplir un programa de cumplimiento en materia de competencia para ser considerado eficaz: implicación de los órganos de dirección, identificación de los riesgos, formación, canales de denuncia, etc. Sin embargo, existe disenso sobre si dichos programas deben de cumplir, única y exclusivamente, una función preventiva o si también han de tenerse en cuenta a la hora de determinar la cuantía de la sanción, en caso de infracción.

64. La Comisión Europea anima a las empresas a elaborar estrategias de cumplimiento normativo, destacando su función preventiva, no teniéndolas en cuenta a la hora de determinar la sanción. No obstante, subraya que, de forma indirecta, la empresa podría ver atenuada su responsabilidad participando en un programa de clemencia o en un procedimiento de transacción.

65. En esta línea, la autoridad de competencia francesa se muestra partidaria de la implementación de programas de cumplimiento en materia de competencia que ayuden a crear una cultura de respeto al Derecho vigente en la materia. Para la ADC, estos programas juegan un importante papel preventivo, disminuyendo la exposición al riesgo de las empresas, pero también "curativo", permitiendo la rápida detección de prácticas anticompetitivas. Optando, en línea con la posición de la Comisión Europea, por no reconocer ninguna reducción de la multa en caso de infracción.

66. Es cierto que el principal objetivo de un programa de cumplimiento no debe de ser en ningún caso el de ser valorado como un elemento moderador de la responsabilidad cuando se produzca la infracción, sino el de crear en el marco de la empresa una cultura de cumplimiento en materia de competencia, que evite que se produzcan tales conductas anticompetitivas (función preventiva). También es cierto que, de producirse la infracción, el programa facilita su rápida detección ${ }^{56} \mathrm{y}$, por ende, la participación en los programas de clemencia y de transacción o cooperación, con las ventajas que ello supone. No obstante, desde nuestro punto de vista, la falta de un aliciente claro y directo, como puede ser la atenuación del importe de la sanción, no incentiva la adopción de medidas de compliance y, en consecuencia, no contribuye a la concienciación sobre la importancia de cumplir las normas de defensa de competencia. Parece conveniente, que las empresas que han dedicado recursos y esfuerzo a generar una cultura de cumplimiento, a través de medidas de compliance, consigan un cierto reconocimiento.

67. Conforme a esta idea, otros países, entre los que se encuentra España, abogan por considerar la existencia de un programa de compliance no solo como un elemento preventivo de conductas anti-

\footnotetext{
${ }^{56}$ Aunque lo más evidente es deducir que contar con un programa de cumplimiento adecuado permite detectar comportamientos anticompetitivos dentro de la propia empresa, señala J. M. Sipos GÁLVEZ, "La implementación de los programas de cumplimiento de la normativa de competencia y su impacto en el régimen sancionador", en E. Ortega Burgos (dir.), Actualidad Civil Mercantil, Tirant Lo Blanch, Valencia, 2019, p. 348, que tampoco cabe descartar que a través de la implantación de estos programas "puedan detectarse conductas anticompetitivas de terceros de las que pueda ser víctima, con la consiguiente posibilidad de denunciarlo a la autoridad o iniciar acciones en los tribunales".
} 
competitivas, sino también como un posible elemento moderador de la responsabilidad, justificando la atenuación de la multa o, incluso, la exoneración del pago.

68. En este sentido, la autoridad de competencia inglesa, reconoce una posible reducción de la multa del 10\%, valorando de forma muy positiva los programas ex post. Incluso, excepcionalmente, se prevé la posibilidad de considerar la concurrencia de una agravante, cuando se haga una mala utilización del programa de compliance, empleándolo para facilitar la infracción u ocultarla.

69. La autoridad de competencia italiana muestra su preferencia por los programas ex ante, contemplando atenuantes para aquellas empresas que cuenten con un programa de cumplimiento, no necesariamente eficaz (el importe de la multa podrá reducirse hasta un $15 \%$, en caso de programas adecuados; hasta un 10\%, en caso de programas no manifiestamente inadecuados; y hasta un 5\%, en caso de programas manifiestamente inadecuados). La AGCM italiana también prevé atenuantes (reducciones de hasta un 5\% del importe de la multa) para aquellas empresas que implementen programas de cumplimiento ex novo.

70. En España, la CNMC, en línea con la Guía italiana, muestra una preferencia por los programas ex ante, previendo reducciones e incluso exoneraciones del pago de la multa, aunque también valora la adopción de medidas de compliance ex post como posible elemento moderador de la sanción.

71. Tanto en España, como en Reino Unido e Italia, se contemplan beneficios para aquellas empresas que implementen programas de cumplimiento en el seno de su empresa, bien sea con anterioridad o con posterioridad a la incoación del expediente sancionador ${ }^{57}$. Estamos de acuerdo con la conveniencia de premiar ambos esfuerzos ${ }^{58}$, no obstante, la opción de las autoridades de competencia española e italiana, mostrando una preferencia por los programas ex ante, parece la más acertada. Opinamos que, una preferencia por los programas ex post podría derivar en una falta de incentivo para implementar medidas de compliance antes de producirse una infracción, viéndose frustrada su función preventiva ${ }^{59}$.

72. De los países analizados, es nuestra autoridad de competencia la que prevé mayores ventajas, llegando a considerar la exoneración del pago de la multa. Para el caso de infracciones muy graves o graves no constitutivas de cártel, afirma la CNMC que "la puesta en conocimiento de la autoridad de una infracción que haya podido ser descubierta gracias al programa de cumplimiento, se haya iniciado o no

${ }^{57}$ En este sentido, Y. Martínez Mata, "Los programas de «compliance» en derecho de la competencia”, cit., afirma que lo relevante no es, a su parecer, "que el programa se implemente antes o después del inicio de un expediente sancionador, siempre que en el primer caso pueda probarse su efectividad generalizada (sin perjuicio de la desviación puntual materializada en la propia infracción) y en el segundo caso pueda evaluarse el rigor y compromiso con el nuevo programa en el marco de eventuales expedientes de vigilancia".

${ }^{58}$ Hay voces contrarias al reconocimiento cualquier tipo de beneficio, en este sentido C. CoHí AnCHÍA, "Los Programas de Cumplimiento en relación con la Normativa de Defensa de la Competencia: en beneficio de todos", Anuario de la competencia, n. ${ }^{\circ}$ 1, 2015, p. 391, antes de la aprobación de la Guía, afirmaba que "el mero hecho de que una empresa adopte un Programa de Cumplimiento no puede premiarse, generaría un efecto perverso, al adoptar un Programa con el objetivo de minorar la multa o sanción, y por tanto haciendo el coste de la infracción mucho menor, por ente, incentivando en cierto modo dichas conductas", y aclaraba, que "por otro lado, si lo que se compensara fuera un Programa de Cumplimiento «efectivo», habría que definir y validar lo que se considera efectivo, lo cual requiere de recursos, y de la adopción de criterios concretos. Sin embargo, el hecho de que un Programa de Cumplimiento falle (lo que daría razón de ser a la imposición de sanciones y a plantearse su reducción en este caso) parece entrar en contradicción con el hecho de que se considere efectivo. En otras palabras: si falla, no está siendo efectivo, no merecía ser considerado como efectivo. ¿Por qué premiar un programa de cumplimiento que ha fallado, luego no era efectivo?”.

${ }^{59}$ Algo crítico con esta postura, se muestra B. Martínez Corral, "Las medidas de self-cleaning y los programas de cumplimento en materia de defensa de la competencia en España", Comunicaciones en propiedad industrial y derecho de la competencia, $\mathrm{n}^{\circ} 89,2020$, p. 241, cuando entiende que "en un expediente sancionador la existencia de un programa ex ante demostraría la ineficacia de dicho programa, mientras que el programa ex post puede suponer un cambio de rumbo de la empresa cuyo compromiso puede ser relevante a futuro". Conviene aclarar que el autor, a pesar de la apreciación, no se muestra contrario a valorar los programas ex ante como elemento moderador de la responsabilidad. En esta misma línea, se pronuncia en el capítulo "Los «Compliance programs" en materia de derecho de defensa de la competencia", en M. A. RECUERDA GIRELA (dir.) Problemas prácticos y actualidad del derecho de la competencia: Anuario de derecho de la competencia, 2016, p. 110. 
un procedimiento sancionador, junto con su colaboración activa y eficaz, constituye una evidencia del compromiso de la empresa con el cumplimiento de las normas de defensa de la competencia, pudiendo ser considerado a los efectos de atenuar su responsabilidad, tal y como establece la LDC, llegando incluso a quedar exonerado del pago de la multa" ${ }^{\prime 0}$. Nuestra autoridad de competencia busca, de este modo, un paralelismo con el tratamiento de las infracciones muy graves constitutivas de cártel. Para estas situaciones, el art. 65 LDC dispone que podrán acogerse al programa de exención del pago de la multa aquellas empresas que sean las primeras que, a juicio de la CNMC, le permitan ordenar el desarrollo de una inspección o le permitan detectar la existencia de un cártel. Es la Ley de Defensa de la Competencia la que prevé la exoneración del pago de la multa en el marco de los programas de clemencia, en los que solo pueden participar las empresas partícipes de un cártel; no existiendo ninguna previsión legal semejante para aquellas empresas autoras de una infracción muy grave o grave no constitutiva de cártel. En este contexto legal, entendemos que la CNMC no está facultada para exonerar del pago de la multa a estas empresas, pudiendo únicamente acordar una reducción ${ }^{61}$.

73. En todos los supuestos previstos por la Guía de la CNMC -consecuencias derivadas de programas eficaces ex ante o ex post-, se prevé la posibilidad de contemplar una atenuación de la multa, que encuentra su base normativa en la lista abierta de atenuantes que describe el art. 64.3 LDC.

En los supuestos de infracción muy grave constitutiva de cártel, en los que la empresa se acoja a un programa de clemencia, facilitando elementos de prueba de la presunta infracción que aporten un valor añadido significativo con respecto a aquéllos de los que ya disponga la CNMC, además de beneficiarse de la reducción prevista en el art. 66 LDC, podrá hacerlo de la derivada de la existencia del programa de compliance.

En el resto de supuestos ${ }^{62}$, también se prevé una posible modulación de la sanción, siempre y cuando se realicen otro tipo de actuaciones que constituyan una evidencia del compromiso de la empresa con el cumplimiento de las normas de defensa de la competencia, tales como la colaboración de forma activa y eficaz durante el procedimiento sancionador, el reconocimiento de los hechos detectados, la terminación inmediata de la conducta o la adopción de decisiones que remedien los perjuicios de la misma para la competencia de forma rápida y voluntaria. Todas estas actuaciones ya están contempladas por el artículo 64.3 LDC, por lo que habría resultado conveniente que, con mayor claridad, la CNMC hubiese aclarado si las empresas que cuentan con medidas de compliance resultan o no merecedoras de una mayor ventaja ${ }^{63}$.

74. La Guía de la CNMC adolece de falta de precisión a la hora de determinar la cuantía de la reducción. Sería más adecuado y favorecedor de la seguridad jurídica, contemplar una referencia al porcentaje en el que puede verse reducida la multa, tal y como hace la autoridad de competencia italiana. En el único expediente sancionador en el que nuestra autoridad de competencia ha tenido oportunidad de aplicar la Guía, se ha reducido el importe de la multa en un $10 \%$, pero, evidentemente, un expediente aislado no constituye un precedente relevante.

\footnotetext{
${ }^{60} \mathrm{CNMC}$, Guía sobre los programas... cit., p. 14.

${ }^{61}$ Con anterioridad a la Guía, sobre la posibilidad de reconocer una exención de la multa, entiende P. PÉrEz FERNÁNDEZ, "La importancia de los programas de cumplimiento (compliance programmes) en las políticas sancionadoras de las autoridades de competencia", cit., "que equivaldría a afirmar que por haber invertido dinero y medios en diseñar e incorporar en el seno de la empresa un programa de cumplimiento bien estructurado y efectivo la empresa queda exenta de pagar cualquier multa y no podrá ser sancionada, por muy grave que hubiese resultado su conducta, en atención a las restricciones a la libre competencia que se derivan de la misma y los daños y perjuicios causados", entendiendo que la atenuante es la "mejor opción para incentivar que las empresas adopten compliance programmes en materia de competencia".

${ }^{62}$ Supuestos descritos en los párrafos 53 a 55 del presente artículo.

${ }^{63}$ C. M. S. Albiñana \& SuÁrez de Lezo, "Los programas de cumplimiento en materia de defensa de la competencia y su consideración como atenuante en los expedientes sancionadores", Alerta competencia, junio de 2012, disponible en: https:// $\mathrm{cms}$.law/en/content/download/79277, entiende, ya antes de la Guía, que la existencia de un programa de compliance puede suponer una atenuante del art. 64 LDC, al interpretarse que estamos antes "la realización de actividades que pongan fin a la infracción o tendentes a la reparación del daño causado; la no aplicación efectiva de las conductas e, incluso, la colaboración activa con la Comisión realizada al margen de los programas de exención y reducción a los que nos hemos referido anteriormente".
} 
75. La CNMC acierta al exigir que los programas de cumplimiento, para que puedan tenerse en cuenta a la hora de mitigar la sanción, cumplan con una serie de requisitos de eficacia. Si el programa no refleja un compromiso serio y eficaz con el cumplimento de las normas de defensa de la competencia, no debería nunca considerarse un elemento moderador de la responsabilidad ${ }^{64}$. La Guía italiana sí prevé una posible reducción de la multa de hasta el 5\% para aquellas empresas infractoras que cuenten con programas manifiestamente inadecuados, pero solo si éstas presentan modificaciones sustanciales al mismo después del inicio del procedimiento sancionador. La autoridad de competencia italiana, valora así las medidas ex post, de mejora del programa ya existente, y lo hace ofreciendo una reducción idéntica, que la que prevé para aquellas empresas que no cuentan con ningún tipo de medida de compliance y las implementan con posterioridad a la apertura del procedimiento sancionador.

76. Resulta criticable la opción de la autoridad de competencia inglesa al considerar que las medidas de compliance puedan acabar siendo consideradas como una circunstancia agravante ${ }^{65}$-nuestra Guía no contiene ningún pronunciamiento parecido- . Aunque CMA reserva la aplicación de la circunstancia agravante a situaciones muy excepcionales, entendemos que una decisión en este sentido provocaría un desincentivo a la implementación de programas de compliance. La Comisión Europea tampoco se muestra partidaria, entendiendo que los esfuerzos en materia de cumplimiento normativo solo pueden suponer un beneficio para la empresa que los adopta ${ }^{66}$.

${ }^{64}$ Y. Martínez Mata, "Los programas de «compliance» en derecho de la competencia”, cit.: "Lo que es evidente, sin embargo es que un programa de compliance que simplemente persiga cubrir el expediente y/o maquillar prácticas dudosas, ni genera esa cultura corporativa de cumplimiento, ni puede ser objeto de ningún tipo de valoración positiva por parte de las autoridades de la competencia".

${ }^{65}$ En esta línea, Y. Martínez Mata, "Los programas de «compliance» en derecho de la competencia”, cit., afirma que "una eventual desviación no debería merecer un acicate ex post, puesto que solo sería muestra de la falta de efectividad del programa de compliance".

${ }^{66}$ Comisión EuRopeA, La importancia de cumplir... cit., punto 4.6.: "Huelga decir que la existencia de un programa de cumplimiento no se considerará circunstancia agravante si las autoridades de control concluyen que hay una infracción. Si el programa no ha dado resultados, la sanción consistirá en la multa impuesta. Dicho de otro modo: un programa de cumplimiento creíble en materia de competencia no puede sino beneficiar a una compañía". 